\title{
LIXIVIAÇÃo DE IMAZETHAPYR + IMAZAPIC EM FUNÇÃo DO MANEJO DE IRRIGAÇÃO DO ARROZ ${ }^{1}$
}

\author{
Imazethapyr + Imazapic Leaching in Lowland Soil as Affected by Rice Irrigation Management \\ MARTINI L.F.D. ${ }^{2}$ AVILA, L.A. ${ }^{3}$ SOUTO, K.M. ${ }^{4}$ CASSOL, G.V. ${ }^{5}$ REFATTI, J.P. ${ }^{5}$ MARCHESAN, E. ${ }^{6}$ e \\ BARROS, C.A.P. ${ }^{7}$
}

\begin{abstract}
RESUMO - Os herbicidas utilizados no sistema Clearfield ${ }^{\circledR}$ de arroz irrigado são persistentes e móveis no solo, portanto práticas de manejo podem influenciar na sua dinâmica no ambiente. O objetivo deste trabalho foi determinar o efeito de três manejos de irrigação da cultura do arroz na lixiviação da mistura formulada dos herbicidas imazethapyr e imazapic, em solo de várzea. O experimento consistiu de um ensaio de campo seguido de um bioensaio. As coletas de amostras de solo foram feitas por meio da retirada de monolitos em áreas submetidas aos diferentes manejos de irrigação do experimento de campo. As amostras foram seccionadas em intervalos de $5 \mathrm{~cm}$, até a profundidade de $30 \mathrm{~cm}$. Os tratamentos foram compostos pelos manejos de irrigação por inundação contínua, intermitente e por banhos (fator A) e pelas profundidades do solo de 0 a $30 \mathrm{~cm}$ (fator B). Foi efetuada a comparação do crescimento de plantas de arroz não tolerantes aos herbicidas, cultivadas em solo submetido aos manejos de irrigação, com o crescimento das plantas em solo com quantidade conhecida dos herbicidas. A irrigação promoveu movimento vertical do herbicida, porém a diferença entre os manejos de irrigação apenas foi observada na camada superficial do solo $(0-5 \mathrm{~cm})$, com menores concentrações na irrigação por banhos. A mistura formulada do herbicida concentrou-se na camada de 5-20 cm de profundidade aos 134 dias após a aplicação.
\end{abstract}

Palavras-chave: bioensaio, estatura de plantas, intoxicação, irrigação intermitente.

ABSTRACT - The herbicides used in Clearfield ${ }^{\mathrm{TM}}$ rice technology are persistent and mobile in soil, and thus, management practices can affect its dynamics. The objective of this study was to determine the effect of three different rice irrigation managements on leaching of the formulated mixture of the herbicides imazethapyr and imazapic in lowland soil. This study consisted of a field experiment followed by bioassay. The bioassay was conducted in a greenhouse of the Department of Biology of the Universidade Federal de Santa Maria in 2009. Soil samples were collected from a field experiment submitted to different rice irrigation managements. These samples were sliced at $5 \mathrm{~cm}$ intervals up to $30 \mathrm{~cm}$ in depth. The treatments included three irrigation managements: continuous flooding, intermittent flooding and flush (factor A) and soil depth of $5 \mathrm{~cm}$ intervals, from 0 to $30 \mathrm{~cm}$ (factor B). The bioassay compared the growth of non-tolerant rice plants grown in soil subjected to the treatments described above, with the plants grown in soil with a known amount of herbicides. Irrigation promotes vertical movement of the herbicide, but the difference between irrigation management is only observed in the topsoil $(0-5 \mathrm{~cm})$, with flush being the treatment with the lower amounts of herbicide at this depth. The herbicide is concentrated at 5-20 cm depth, 134 days after the product is applied in lowland soil.

Keywords: bioassay, intermittent irrigation, injury, plant height.

1 Recebido para publicação em 15.4.2010 e na forma revisada em 18.2.2011.

Parte da dissertação de mestrado do primeiro autor.

2 Doutorando(a), Programa de Pós-Graduação em Fitossanidade, Universidade Federal de Pelotas - UFPel, Bolsista CAPES;

${ }^{3}$ Professor Adjunto, Departamento de Fitossanidade, UFPel, Caixa Postal 354, 96010-900 Pelotas-RS, Brasil, bolsista CNPq, $<$ laavilabr@gmail.com>; ${ }^{4}$ Doutorando(a), Programa de Pós-Graduação em Agronomia, Universidade Federal de Santa Maria UFSM, bolsista CAPES; ${ }^{5}$ Mestrando(a), Programa de Pós-Graduação em Fitossanidade, UFPel, bolsista CAPES; ${ }^{6}$ Professor Titular, Departamento de Fitotecnia, UFSM, bolsista CNPq; ${ }^{7}$ Mestrando(a), Programa de Pós-Graduação em Ciência do Solo, UFSM, bolsista CAPES.

Planta Daninha, Viçosa-MG, v. 29, n. 1, p. 185-193, 2011 


\section{INTRODUÇÃO}

A tecnologia Clearfield ${ }^{\circledR}$ foi introduzida como uma ferramenta para o eficiente controle químico do arroz-vermelho, principal planta daninha das lavouras de arroz irrigado (Agostinetto et al., 2001; Villa et al., 2006; Santos et al., 2008), o que contribuiu para o acréscimo da produtividade média de grãos de arroz do Estado. Os herbicidas utilizados em tal tecnologia pertencem ao grupo químico das imidazolinonas, as quais possuem elevado risco de contaminação de águas subterrâneas devido ao seu prolongado efeito residual e alta solubilidade (Vischetti, 1995), com grande mobilidade no solo (Jourdan et al., 1998; Firmino et al., 2008).

Nesse grupo de herbicidas destaca-se o imazethapyr, cuja persistência é influenciada pelas características do solo, como textura, teor de matéria orgânica e umidade (Goetz, 1990), sendo diretamente dependente do metabolismo microbiano aeróbico - principal mecanismo de dissipação das imidazolinonas no solo (Loux \& Reese, 1993; Flint \& Witt, 1997). Contudo, em condições de anaerobiose a sua degradação é praticamente nula (Mangels, 1991), caracterizando a maior persistência em solos hidromórficos, como os de várzea, podendo ocorrer efeito residual sobre o arroz suscetível mesmo após 361 dias da aplicação (Villa et al., 2006).

O sistema produtivo de arroz irrigado caracteriza-se pelo elevado volume de água utilizado para irrigação, variando de $6.000 \mathrm{~m}^{3} \mathrm{ha}^{-1}$ (Machado et al., 2006) a mais de $11.000 \mathrm{~m}^{3} \mathrm{ha}^{-1}$ por ciclo (Toescher et al., 1997), onde as plantas necessitam para o seu desenvolvimento (evapotranspiração) em torno de 4.000 a $7.000 \mathrm{~m}^{3} \mathrm{ha}^{-1}$ (Tabbal et al., 2002). Essa demanda é reflexo da ocorrência de perdas por escoamento superficial, evaporação, fluxo lateral e percolação de água no solo (Stone, 2005). As perdas por percolação podem ser influenciadas por propriedades físicas do solo, largura e estado de consolidação e de conservação das taipas, preparo do solo e por cargas de pressão, decorrentes da altura da lâmina de irrigação (Borrel et al., 1997; Tuong \& Bhuiyan, 1999; Walker, 1999; Bouman \& Tuong, 2001; Tabbal et al., 2002; Tuong et al., 2005). A percolação é considerada o principal componente das perdas de água em solos arenosos, ocasionando o aumento da lixiviação de nutrientes (Stone, 2005) e, possivelmente, de agrotóxicos, proporcionando a contaminação de águas subterrâneas, as quais muitas vezes podem servir de fonte potável para o consumo humano.

A irrigação intermitente do arroz irrigado, além de manter elevados os níveis de produtividade quando comparada à irrigação contínua (Belder, 2004; Mezzomo, 2009), permite a economia de água para irrigação (Borrel et al., 1997; Stone, 2005; Mezzomo, 2009). A referida economia é proporcionada pelo melhor aproveitamento das precipitações (Borrel et al., 1997; Toescher et al., 1997) e pela diminuição das perdas por escoamento superficial (Stone, 2005; Watanabe et al., 2006, 2007; Mezzomo, 2009) e por percolação (Borrel et al., 1997; Tuong \& Bhuiyan, 1999; Tabbal et al., 2002; Stone 2005; Tuong et al., 2005). Dessa forma, com a redução da percolação de água, pode haver menor lixiviação de agrotóxicos no solo e menor risco de contaminação de lençóis subterrâneos.

O manejo de irrigação da cultura do arroz pode afetar a lixiviação e a concentração dos herbicidas imazethapyr e imazapic ao longo do perfil do solo. Dessa forma, o presente trabalho teve por objetivo determinar o efeito de três manejos de irrigação do arroz na lixiviação dos referidos herbicidas em solo de várzea.

\section{MATERIAL E MÉTODOS}

O trabalho foi composto por um experimento de campo, seguido de um bioensaio realizado em casa de vegetação.

Experimento de campo: Foi conduzido no ano agrícola de 2008/09 em sistema Clearfield ${ }^{\circledR}$ de arroz irrigado, na área de várzea sistematizada do Departamento de Fitotecnia da Universidade Federal de Santa Maria, no sistema de semeadura direta. O solo é classificado como Planossolo Hidromórfico Eutrófico Arênico, com classe textural franco-siltosa, com as seguintes características: $\mathrm{pH}_{\text {água }}(1: 1)$ $=5,1$; teor de argila $=21 \%$; teor de matéria orgânica $=1,9 \% ; \mathrm{P}=18 \mathrm{mg} \mathrm{dm}^{-3} ; \mathrm{K}=36 \mathrm{mg} \mathrm{dm}^{-3}$; $\mathrm{Ca}=4,8 \mathrm{cmol}_{\mathrm{c}} \mathrm{dm}^{-3} ; \mathrm{Mg}=1,8 \mathrm{cmol}_{\mathrm{c}} \mathrm{dm}^{-3} ; \mathrm{Al}=$ $1,7 \mathrm{cmol}_{\mathrm{c}} \mathrm{dm}^{-3} ; \mathrm{e}$ indice $\mathrm{SMP}=6,4$.

O experimento foi organizado no delineamento inteiramente casualizado, com quatro 
repetições. Os tratamentos foram compostos por três manejos de irrigação: manejo de irrigação por inundação contínua, intermitente e por banhos. Os dois primeiros foram instalados em área com histórico de utilização da tecnologia Clearfield (safra 2007-2008), aplicado 492 dias antes da coleta do solo do ano em questão. Todos os tratamentos receberam o correspondente a $1 \mathrm{~L} \mathrm{ha}^{-1}$ da mistura formulada de imazethapyr e imazapic (75 e 25 g i.a. $L^{1}$, respectivamente), aspergido no estádio de V3-V4 aos 16 DAE. Logo após a aplicação, foi iniciada a irrigação. O manejo de irrigação por inundação contínua caracterizou-se pela manutenção de uma lâmina de irrigação constante em $10 \mathrm{~cm}$ acima do nivel médio do solo. Na irrigação intermitente, permitia-se a total evapotranspiração da lâmina de irrigação (solo encharcado) e, a partir desse momento, fazia-se a reposição da lâmina de irrigação novamente a $10 \mathrm{~cm}$. O manejo de irrigação por banhos foi efetuado com irrigações de $30 \mathrm{~mm}$ de volume de água, o qual foi baseado nas condições meteorológicas da região, bem como no estádio fenológico da cultura e previsões de chuva; o requerimento diário de água foi calculado por meio do cálculo da evapotranspiração, pela equação de Penman-Monteith. Nos três tratamentos, a irrigação foi cessada quando as plantas de arroz se encontravam no estádio R7 (110 DAE), conforme escala fenológica proposta por Counce et al. (2000), totalizando um período total de 94 dias de irrigação.

Aos 134 dias após a aplicação dos herbicidas (DAA), foram coletadas amostras de solo com a finalidade de conduzir um bioensaio para determinação da concentração dos herbicidas ao longo do perfil. As referidas coletas foram feitas por meio da retirada de monolitos (amostras não deformadas de solo), com auxílio de tubos de PVC $(10 \mathrm{~cm}$ de diâmetro e $50 \mathrm{~cm}$ de comprimento). O tubo de PVC foi introduzido no solo com auxilio de um batedor até a profundidade de aproximadamente $40 \mathrm{~cm}$ e, após, retirado do solo com auxílio de pá de corte, evitando a deformação da amostra. Logo após a remoção dos monolitos, estes foram seccionados em intervalos de $5 \mathrm{~cm}$, até o correspondente a $30 \mathrm{~cm}$ de profundidade.

No experimento de campo foi monitorada a altura do lençol freático, o que foi feito através da instalação de poços de observação, com a introdução de canos de PVC de $50 \mathrm{~mm}$ de diâmetro a $1 \mathrm{~m}$ de profundidade no solo. Esses poços foram usados para medição do lençol freático no manejo de irrigação por banhos. Já nos manejos de irrigação contínuo e intermitente foi considerada a altura da lâmina de irrigação.

Bioensaio: As amostras de solo coletadas em campo foram usadas para realização de um bioensaio, usando o cultivar IRGA 417 como bioindicador do herbicida. O bioensaio foi conduzido no ano de 2009, em casa de vegetação do Setor de Herbologia do Departamento de Ciências Biológicas da Universidade Federal de Santa Maria. O experimento foi arranjado em blocos completamente casualizados, com os tratamentos em esquema fatorial, com quatro repetições, em que o fator A consistiu no manejo de irrigação utilizado no experimento de campo (A1: manejo contínuo, A2: intermitente e A3: manejo por banhos); e o fator $\mathrm{B}$ consistiu das profundidades das amostras de solo (0-5, 5-10, 10-15, 15-20, 2025 e $25-30 \mathrm{~cm})$.

Foi construída uma curva de calibração em solo que não recebeu a aplicação do herbicida (sem resíduo), para cada profundidade considerada, com o intuito de eliminar o efeito do crescimento das plantas em solo de diferentes profundidades. Nas profundidades de 0-5, 5-10 e $10-15 \mathrm{~cm}$, foi aplicado o correspondente às doses de 0, 50, 100, 300, 500 e $800 \mathrm{~mL} \mathrm{ha}^{-1}$ da mistura formulada de imazethapyr e imazapic. Já nas profundidades de 15-20, 20-25 e 25-30 cm foi aplicado o herbicida nas doses de 0,10, 25, 50, 200 e $500 \mathrm{~mL} \mathrm{ha}^{-1}$. Foram aplicadas doses menores nas profundidades maiores, pois normalmente encontramse menores quantidades de herbicidas nas profundidades de $15-25 \mathrm{~cm}$ (Kraemer et al., 2009). Para as curvas de calibração, foi ajustado um modelo sigmoidal de três parâmetros. Essas curvas foram usadas para estimar a quantidade de herbicida presente em cada profundidade (amostra do experimento de campo).

As amostras de solo, previamente seccionadas em $5 \mathrm{~cm}$, provenientes das áreas tratadas ou da área sem tratamento com herbicida foram destorroadas e acondicionadas 
em potes de $500 \mathrm{~mL}$ de capacidade. Foi adicionada água para desestruturação do solo e formação do lodo, para semeadura do arroz no sistema pré-germinado.

No solo utilizado para a curva de calibração, o herbicida foi aplicado com pipetas automáticas, retirando quantidades diferenciadas para cada dose de uma solução de $150 \mu \mathrm{L} \mathrm{L}^{-1}$ de concentração da mistura formulada dos herbicidas. Após a aplicação do herbicida, o solo foi deixado em repouso por um periodo de 48 horas, para o equilíbrio de sorção do herbicida com o solo. Após esse período, seis sementes de arroz pré-germinadas foram semeadas em cada unidade experimental (UE), sendo feito desbaste uma semana depois da semeadura, deixando-se quatro plântulas por pote.

As sementes foram previamente tratadas com o inseticida fipronil na dose de $37,5 \mathrm{~g}$ i.a. por $100 \mathrm{~kg}$ de sementes. A adubação de base foi realizada anteriormente à semeadura, sendo feita a homogeneização em cada unidade experimental, com dose correspondente a $450 \mathrm{~kg} \mathrm{ha}^{-1}$ de fertilizante de fórmula 05-20-30 (N-P-K). A adubação nitrogenada de cobertura foi efetuada quando o arroz irrigado encontrava-se no estádio de 3-4 folhas (V3-V4), com aplicação do equivalente a $70 \mathrm{~kg} \mathrm{ha}^{-1} \mathrm{de} \mathrm{N}$, na forma de ureia, sobre lâmina de água.

Os parâmetros avaliados aos 7, 14 e 21 dias após a semeadura do arroz irrigado foram: avaliação visual de intoxicação das plantas de arroz pelo herbicida, com notas variando de 0 (sem efeito do herbicida) a 100\% (plantas mortas pela ação do herbicida), e estatura de plantas aos 7, 14 e 21 dias após a semeadura (DAS). Essas respostas biológicas foram usadas para o cálculo da concentração do herbicida no solo, conforme descrito anteriormente.

Subamostras de solo de cada profundidade foram usadas para determinação do $\mathrm{pH}$ em água (1:1); a partir desses resultados, com base no pKa dos herbicidas (3,9) (Senseman, 2007), foi calculada a porcentagem de herbicida associada e dissociada, por meio da equação de Henderson-Hasselbach:

$$
p H=p K a+\log \frac{\left[A^{-}\right]}{[H A]}
$$

em que $A^{-}=$porção dissociada; e $H A=$ porção associada.

Os dados foram submetidos aos testes das pressuposições do modelo matemático (normalidade e homogeneidade das variâncias) e logo submetidos à análise de variância e ao teste de Tukey $(\mathrm{p} \leq 0,05)$.

\section{RESULTADOS E DISCUSSÃO}

Todos os dados analisados seguiram a distribuição normal e não foi necessário transformação. Não houve diferença significativa entre os métodos de estimativa da quantidade total de herbicidas no solo (0 a $30 \mathrm{~cm}$ ); dessa forma, os valores obtidos pela avaliação de estatura de plantas e pela avaliação visual de intoxicação foram combinados. Os resultados demonstraram que houve diferenças entre os manejos de irrigação para a variável quantidade total estimada de herbicida (Figura 1), com destaque para o manejo de irrigação por banhos, significativamente menor que os demais tratamentos. É válido ressaltar que nesse experimento de bioensaio é avaliado apenas o efeito da mistura formulada composta pelos herbicidas imazethapyr e imazapic, sem possibilidade de discriminação da concentração de cada princípio ativo, que compõem essa formulação.

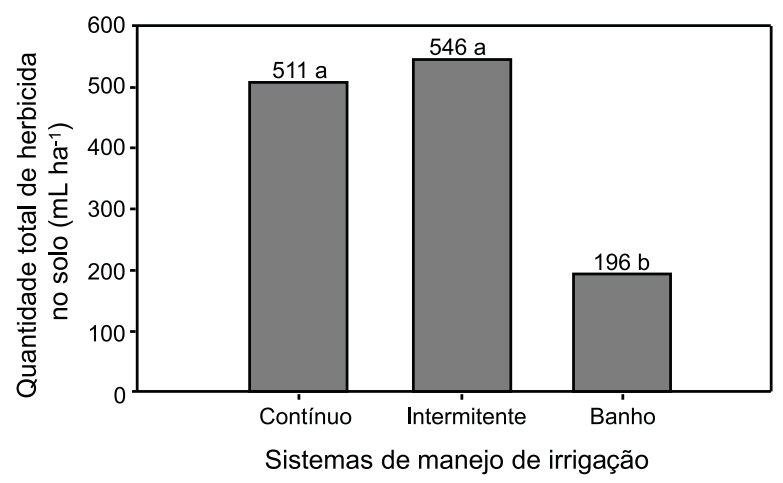

* Médias não seguidas pela mesma letra diferem pelo teste de Tukey $(\mathrm{p} \leq 0,05)$.

Figura 1 - Quantidade total estimada de herbicidas $\left(\mathrm{mL} \mathrm{ha}{ }^{-1}\right)$ composta pela mistura formulada de imazethapyr e imazapic $\left(75+25\right.$ g i.a L $\left.{ }^{-1}\right)$, no somatório das quantidades encontradas nas profundidades de 0 a $30 \mathrm{~cm}$, aos 134 DAA, nos manejos de irrigação contínuo, intermitente e por banhos de arroz irrigado. Santa Maria-RS. 2009. 
A menor quantidade de herbicida encontrada no manejo de irrigação por banhos ocorreu porque esse tratamento foi inserido no segundo ano de cultivo, em área sem o histórico de aplicação dos herbicidas. Já os manejos de irrigação contínuo e intermitente receberam o herbicida por dois anos consecutivos (no ano anterior e no ano em questão) e, devido às condições anaeróbicas da área experimental durante o período de alagamento e entressafra (inverno chuvoso) anteriores à instalação do experimento, proporcionaram menor degradação e consequente maior quantidade estimada de herbicidas, em comparação ao tratamento que recebeu a aplicação dos herbicidas em apenas um ano.

A principal via de degradação das imidazolinonas ocorre principalmente pela ação de microrganismos aeróbicos, sendo praticamente nula em condições de anaerobiose (Mangels, 1991), promovendo elevada persistência dos herbicidas imazethapyr e imazapic em solos hidromórficos com intoxicação verificada em arroz não tolerante semeado 361 dias após a aplicação (Villa et al., 2006).

Para avaliar o efeito do manejo de irrigação sobre o movimento vertical do herbicida, foi efetuada a análise da variância envolvendo os fatores manejos de irrigação (fator A) e profundidades no perfil do solo (fator B) para cada método de quantificação: estatura e avaliação visual de intoxicação de plantas pelo herbicida. Foi verificada interação significativa entre os fatores, sendo posteriormente efetuado o desdobramento da interação do fator profundidades, dentro de cada manejo de irrigação, separadamente para cada método de avaliação.

Para quantificação de herbicida a partir da análise da estatura de plantas, o total presente em cada amostra de solo estimada por meio da curva de calibração interagiu com os fatores manejos de irrigação e profundidade no perfil do solo, indicando que os manejos de irrigação apresentam comportamento diferenciado para profundidade (dados não mostrados). Os dados não foram mostrados, pois a comparação das quantidades de herbicidas entre tratamentos nas diferentes profundidades não é possivel, visto que o manejo por banhos recebeu aplicação do herbicida apenas um ano, ficando com uma dose aplicada diferente daquela observada nos manejos contínuo e intermitente. Além de a dose ser diferente, os herbicidas foram aplicados em épocas distintas. Assim, para fins de comparação, as concentrações nas diferentes profundidades foram transformadas para percentual de herbicida encontrado em cada profundidade, em relação ao total encontrado em cada parcela (Figura 2). Essa comparação servirá como subsídio para estimar o comportamento do movimento do herbicida nos três sistemas de manejo.

Houve diferença significativa entre os manejos de irrigação apenas na profundidade de $0-5 \mathrm{~cm}$, em que o manejo por banhos apresentou menor concentração que os demais tratamentos. Esse comportamento pode ser atribuído à maior aeração do solo, devido à ausência da lâmina de irrigação, proporcionando condição adequada para a degradação microbiana aeróbica, que é a principal via de degradação desses herbicidas no solo (Mangels, 1991; Flint \& Witt, 1997). Na comparação entre os manejos contínuo e intermitente, não se verificou diferença na profundidade de $0-5 \mathrm{~cm}$, pois a condição de alagamento dos dois tratamentos proporcionou condição anaeróbica, sendo a degradação das imidazolinonas praticamente bastante baixa, conforme supracitado.

A menor quantidade de herbicida na camada superficial do manejo de irrigação por banhos, além da ausência de residual, pode ser relacionada à maior oscilação do nivel do lençol freático (Figura 3), demonstrando que a elevação do lençol freático a cada evento de irrigação e/ou chuva pode promover movimento ascendente do herbicida juntamente com a água ou por arraste pelas forças de evaporação, colocando-o numa região com condições ideais para degradação microbiana, devido à maior aeração e temperatura (Wik \& Reinhardt, 2001).

A maior quantidade de herbicida nos manejos de irrigação contínuo e por banhos localizou-se na camada de $5-15 \mathrm{~cm}$, com 66 e $76 \%$ da quantidade total encontrada, respectivamente. Quanto ao manejo intermitente, a maior concentração de herbicidas localizouse na camada de $5-20 \mathrm{~cm}$, com $84 \%$ do total encontrado. Esses resultados foram semelhantes aos observados por Jourdan (1998), 
Porcentagem de herbicida (\%)

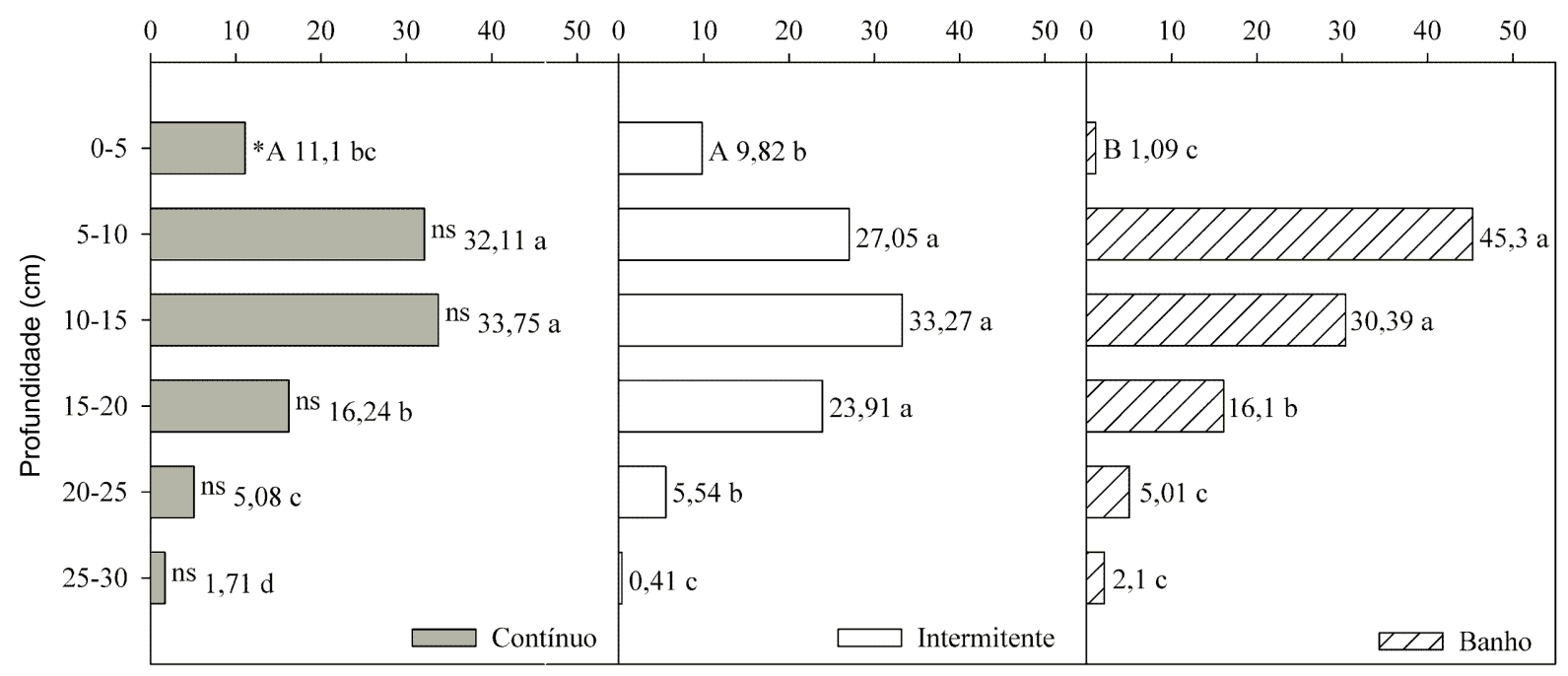

* Médias antecedidas por letras maiúsculas distintas na linha (manejos) e seguidas por distintas letras minúsculas na coluna (profundidades) diferem pelo teste de Tukey $(\mathrm{p} \leq 0,05)$.

Figura 2 - Porcentagem de herbicidas imazethapyr e imazapic encontrada aos 134 DAA em diferentes profundidades do solo, nos manejos de irrigação contínuo, intermitente e por banhos de arroz irrigado, estimada com base na avaliação de estatura de plantas. Santa Maria-RS. 2009.

que, em bioensaio com colunas de solo, observou a maior concentração de imazethapyr na camada de $0-15 \mathrm{~cm}$, e aos dados de Kraemer et al. (2009), os quais concluíram que a maior quantidade de herbicida é encontrada na camada de 5-15 cm de profundidade, em área cultivada sob plantio direto, demonstrando que, mesmo em solos hidromórficos de baixa condutividade hidráulica, o herbicida imazethapyr lixivia até $20 \mathrm{~cm}$. Além disso, Jourdan (1998) demonstrou que o herbicida imazethapyr, após cinco dias de sua aplicação e ocorrência de chuva moderada, foi detectado a $15-20 \mathrm{~cm}$ de profundidade, podendo alcançar até $30 \mathrm{~cm}$, depois de 30 dias.

No que se refere às concentrações de herbicidas estimadas a partir da avaliação visual de intoxicação das plantas, foi verificada interação somente entre os fatores manejos de irrigação e profundidades, sendo somente feita a análise do movimento vertical do herbicida em cada manejo de irrigação. Para fins de comparação, conforme supracitado, as concentrações de herbicida nas profundidades foram transformadas para percentual do total encontrado (Figura 4), porém não houve diferença entre tratamentos em nenhuma das profundidades avaliadas. Semelhantemente aos resultados obtidos por meio da avaliação de estatura de plantas, a maior concentração de herbicidas se deu na camada de $5-15 \mathrm{~cm}$, com $72 \%$; na camada de $5-20 \mathrm{~cm}$, com $86 \%$; e na

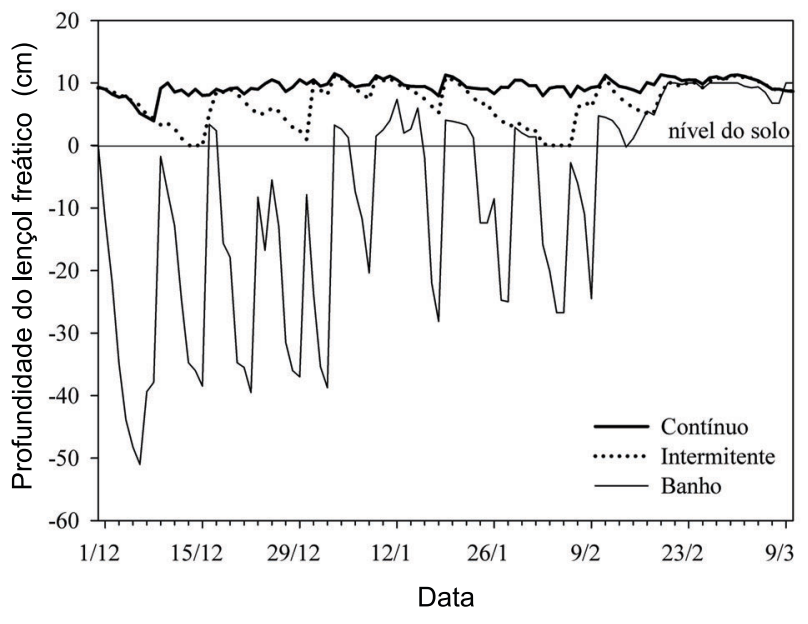

Figura 3 - Profundidade do lençol freático, nos manejos de irrigação contínuo, intermitente e por banhos de arroz irrigado. Santa Maria-RS. 2009. 
camada de $5-10 \mathrm{~cm}$, com $51 \%$ do total encontrado, para os manejos de irrigação contínuo, intermitente e por banhos, respectivamente. Esses resultados mostram que há estreita relação entre as avaliações de estatura e a avaliação visual de intoxicação das plantas, demonstrando consistência dos resultados; isso caracteriza uma adequada e econômica metodologia para estudos relacionados à persistência de moléculas de imidazolinonas em solos de cultivo de arroz irrigado.

Conforme mencionado, a dinâmica dos referidos herbicidas no solo é muito influenciada pelo $\mathrm{pH}$. No entanto, verifica-se que os níveis de $\mathrm{pH}$ encontrados nas diferentes profundidades (Figura 5) são relativamente uniformes, não afetando significativamente

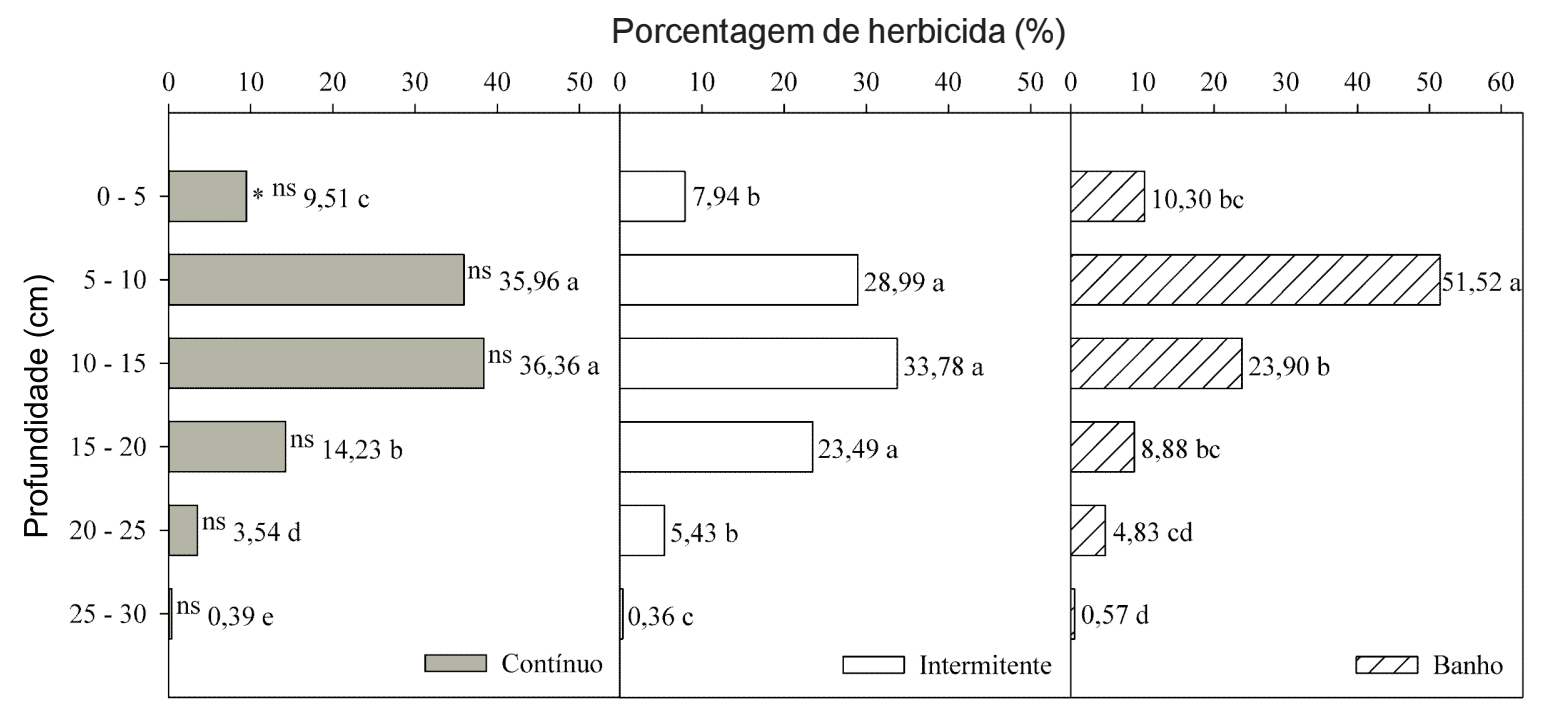

* Médias não antecedidas pela mesma letra minúscula diferem pelo teste de Tukey $(\mathrm{p} \leq 0,05)$.

Figura 4 - Porcentagem de herbicidas imazethapyr e imazapic encontrada aos 134 DAA em diferentes profundidades do solo, nos manejos de irrigação contínuo, intermitente e por banhos de arroz irrigado, estimada com base na avaliação visual de intoxicação das plantas pelo herbicida. Santa Maria-RS. 2009.

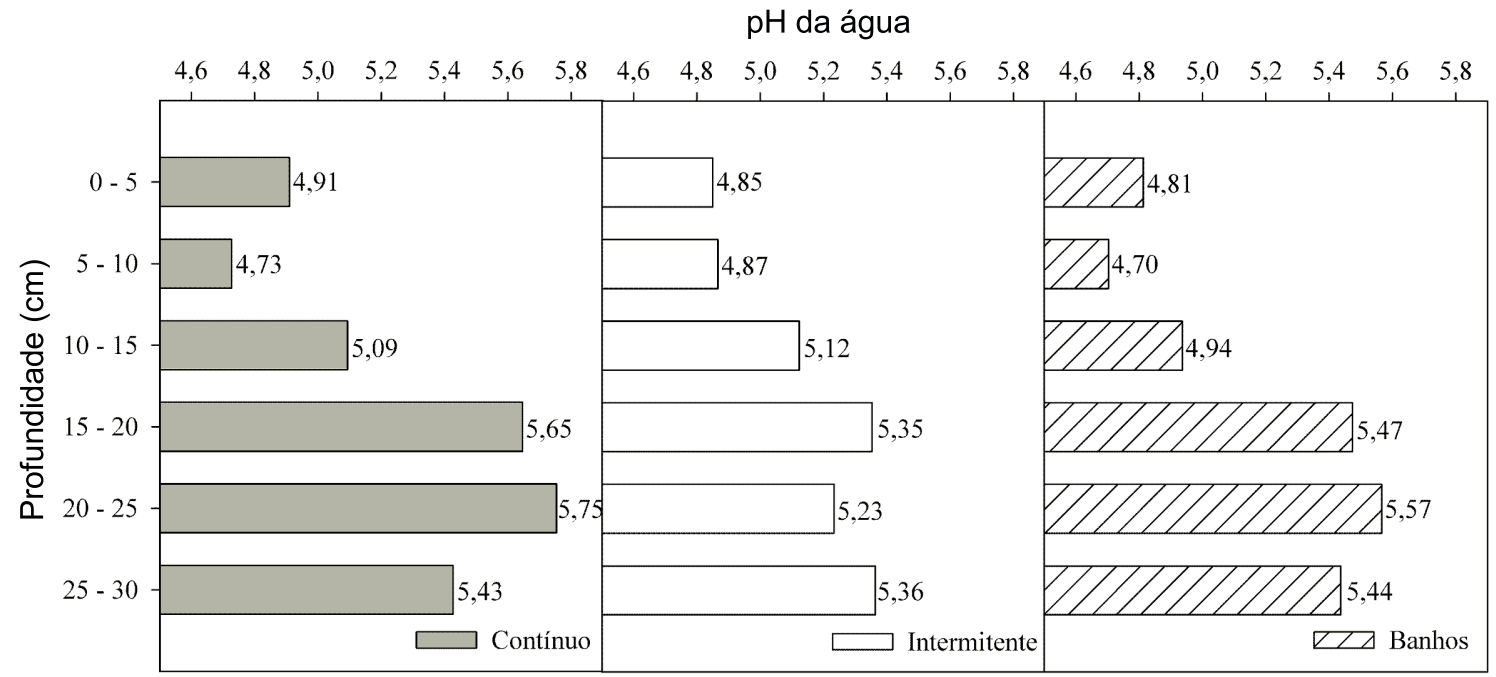

Figura 5 - pH do solo em água em diferentes profundidades no perfil aos 134 DAA, nos manejos de irrigação contínuo, intermitente e por banhos de arroz irrigado. Santa Maria-RS. 2009. 


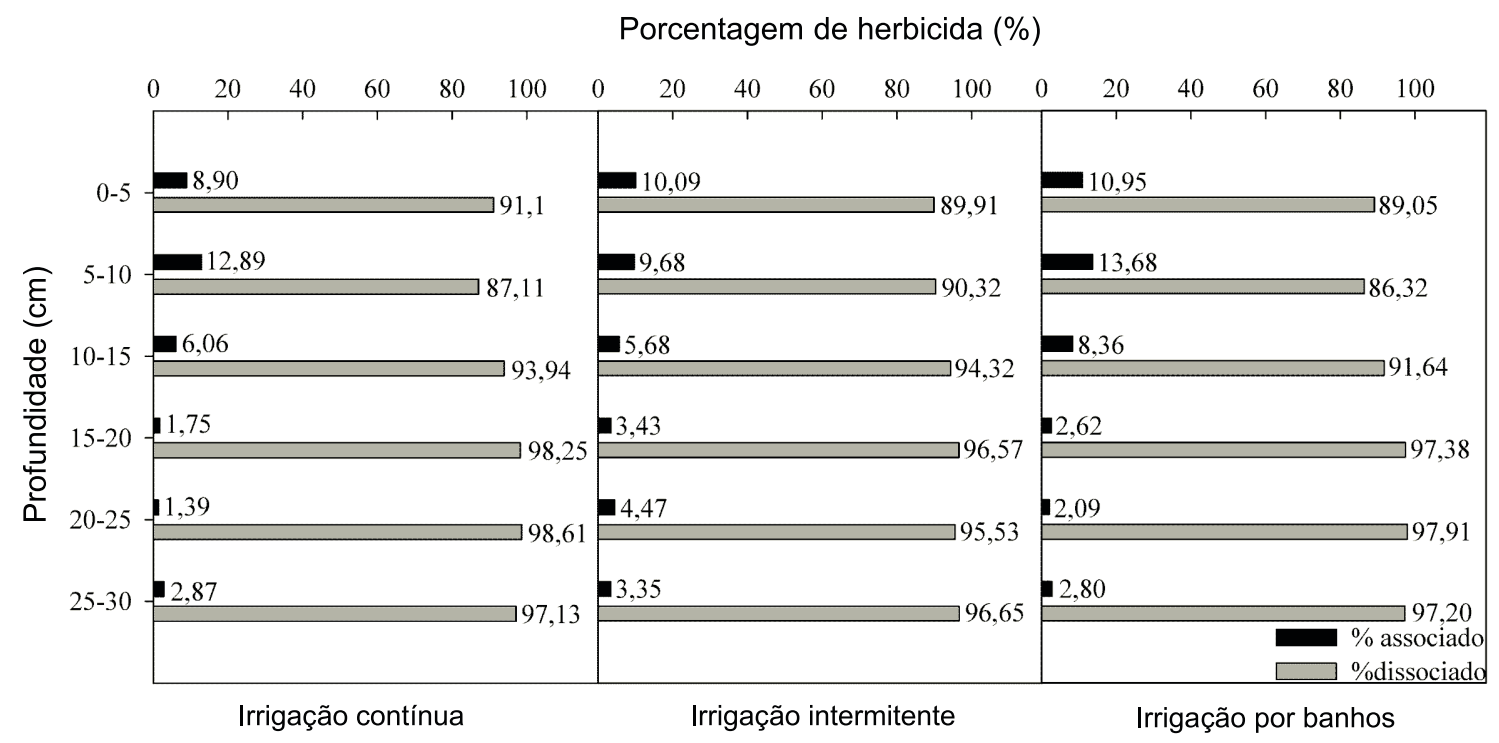

Figura 6 - Porcentagem de herbicida associado e dissociado com base na equação de Henderson-Hasselbach para diferentes profundidades, nos manejos de irrigação contínuo, intermitente e por banhos de arroz irrigado. Santa Maria-RS. 2009.

seu movimento vertical no solo, pois nos diferentes tratamentos a porcentagem de herbicida dissociado não é inferior a 87, 89 e $86 \%$ para os manejos de irrigação contínuo, intermitente e por banhos, respectivamente (Figura 6).

O efeito da altura da lâmina de irrigação dos diferenciados manejos sobre a lixiviação dos herbicidas em estudo pode ser mais pronunciado em solos com a camada compactada profunda e permeável (Bouman et al., 1994), o que não se verificou no presente estudo, no qual havia uma camada semi-impermeável a $15 \mathrm{~cm}$ de profundidade, também chamada de "pé de arado" ou "hardpans". Essas camadas semi-impermeáveis podem limitar o movimento tanto de nutrientes quanto de agrotóxicos para porções mais profundas (Wik \& Reinhardt, 2001).

O herbicida composto pela mistura formulada de imazethapyr e imazapic concentra-se na camada de $5-20 \mathrm{~cm}$ de profundidade aos 134 dias após a aplicação do produto em solo de várzea, indicando ser passivel de movimentação ao longo do perfil do solo, apresentando potencial de contaminação do lençol freático. A irrigação, independentemente de como manejada, promoveu movimento vertical do herbicida, porém apenas foi observada diferença entre os manejos de irrigação na camada superficial do solo $(0,5 \mathrm{~cm})$, evidenciando o favorecimento de sua degradação microbiana aeróbica no manejo de irrigação por banhos.

\section{AGRADECIMENTOS}

Ao CNPq, pela bolsa de Produtividade em Pesquisa de Luis Avila e Enio Marchesan e pelo financiamento do experimento através do Edital MCT/CNPq 14/2008 - Universal, processo 471403/2008-3-Universal. À CAPES, pela bolsa de Mestrado de Luiz Fernando Martini e Kelen Müller Souto. À Universidade Federal de Santa Maria, pela disponibilidade de sua estrutura e viabilização das pesquisas realizadas. Ao professor Sylvio Bidel Dornelles, pelo empréstimo da casa de vegetação para condução do ensaio. Ao Engo-Agro, M.Sc. Rafael Friguetto Mezzomo, pela sua colaboração para a realização do experimento de campo.

\section{LITERATURA CITADA}

AGOSTINETTO, D. et al. Arroz-vermelho: ecofisiologia e estratégias de controle. Ci. Rural, v. 31, n. 2, p. 341-349, 2001.

BELDER, P. et al. Effect of water-saving irrigation on rice yield and water use in typical lowland conditions in Asia. Agric. Water Manag., v. 65, n. 3, p. 193-210, 2004. 
BORRELL, A.; GARSIDE, A.; FUKAI, S. Improving efficiency of water use for irrigated rice in a semi-arid tropical environment. Field Crop Res., v. 52, n. 3, p. 231-248, 1997.

BOUMAN, B. A. M. et al. Water use efficiency of flooded rice fields. II. Percolation and seepage losses. Agric. Water Manag., v. 26, n. 4, p. 291-304, 1994.

BOUMAN, B. A. M.; TUONG, T. P. Field water management to save water and increase its productivity in irrigated lowland rice. Agric. Water Manag., v. 49, n. 1, p. $11-30,2001$

COUNCE, P. A. et al. A uniform, objective, and adaptative system for expressing rice development. Crop Sci., v. 40, n. 2, p. 436-443, 2000.

FIRMINO, L. E. et al. Movimento do herbicida imazapyr no perfil de solos tropicais. Planta Daninha, v. 26, n. 1, p. 223-230, 2008.

FLINT, J. L.; WITT, W. W. Microbial degradation of imazaquin and imazethapyr. Weed Sci., v. 45, n. 4, p. 586$591,1997$.

GOETZ, A. et al. Degradation and field persistence of imazethapyr. Weed Sci., v. 38, n. 4-5, p. 421-428, 1990.

JOURDAN, S. W. et al. Imazethapyr bioactivity and movement in soil. Weed Sci., v. 46, n. 5, p. 608-613, 1998.

KRAEMER, A. F. et al. Lixiviação do imazethapyr em solo de várzea sob dois sistemas de manejo. Ci. Rural, v. 39, n. 6 , p. $1660-1666,2009$.

LOUX, M. M.; REESE, K. Effect of soil type and $\mathrm{pH}$ on persistence and carryover of imidazolinones herbicides. Weed Technol., v. 7, n. 2, p. 452-458, 1993.

MANGELS, G. Behavior of the imidazolinone herbicides in soil: a review of the literature. In: SHANER, D. L.; O'CONNOR, S. L. (Eds.). The imidazolinone herbicides Boca Raton: CRC Press, 1991. p. 191-209.

MACHADO, S. L. O. et al. Consumo de água e perdas de nutrientes e de sedimentos na água de drenagem inicial de arroz irrigado. Ci. Rural, Santa Maria, v. 36, n. 1, p. 65-71, 2006.

MEZZOMO, R. F. Irrigação contínua e intermitente em arroz irrigado: uso de água, eficiência agronômica e dissipação de imazethapyr, imazapic e fipronil. 2009. 61 f. Dissertação (Mestrado em Agronomia) - Universidade Federal de Santa Maria, Santa Maria, 2009.
SANTOS, F. M. et al. Persistência dos herbicidas imazethapyr e clomazone em lâmina de água do arroz irrigado. Planta Daninha, v. 26, n. 4, p. 875-881, 2008.

SENSEMAN, S. A. (Ed.). Herbicide handbook. 9.ed. Lawrence: Weed Science Society of America, 2007. 458 p.

STONE, L. F. Eficiência do uso da água na cultura do arroz irrigado. Santo Antônio de Goiás: Embrapa Arroz e Feijão, 2005. 48 p.

TABBAL, D. F. et al. On-farm strategies for reducing water input in irrigated rice: case studies in the Philippines. Agric. Water Manag., v. 56, n. 2, p. 93-112, 2002.

TOESCHER, C. F.; RIGHES, A. A.; CARLESSO, R. Volume de água aplicada e produtividade do arroz sob diferentes métodos de irrigação. R. Fac. Zootec. Vet. Agron., v. 4, n. 1, p. $75-79,1997$

TUONG, T. P.; BHUIYAN, S. I. Increasing water-use efficiency in rice production: farm-level perspectives. Agric. Water Manag., v. 40, n. 1, p. 117-122, 1999.

TUONG, T. P.; BOUMAN, B. A. M.; MORTIMER, M. More rice, less water - Integrated approaches for increasing water productivity in irrigated rice-based systems in Asia. Plant Produc. Sci., v. 8, n. 3, p. 231-241, 2005

VILLA, S. C. C. et al. Arroz tolerante a imidazolinonas: controle do arroz-vermelho, fluxo gênico e efeito residual do herbicida em culturas sucessoras não-tolerantes.

Planta Daninha, v. 24, n. 4, p. 761-768, 2006.

VISCHETTI, C. Measured and simulated persistence of imazethapyr in soil. Bull. Environ. Contam. Toxicol., v. 54, n. 3, p. 420-427, 1995.

WALKER, S. H. Causes of high water losses from irrigated rice fields: Field measurements and results from analogue and digital models. Agric. Water Manag., v. 40, n. 1, p. 123-127, 1999.

WATANABE, $H$. et al. Effect of water management practice on pesticide behavior in paddy water. Agric. Water Manag., v. 88 , n. $1-3$, p. $132-140,2007$

WATANABE, H.; KAKEGAWA, Y.; VU, S. H. Evaluation of the management practice for controlling herbicide runoff from paddy fields using intermittent and spillover-irrigation schemes. Paddy Water Environ., v. 4, n. 1, p. 21-28, 2006.

WYK, L. J. V.; REINHARDT, C. F. A bioassay technique detects imazethapyr leaching and liming-dependent activity. Weed Sci., v. 15, n. 3, p. 1-6, 2001 